\section{Regulators to work together on clarifying 'serious' fitness to practise}

\section{By Adrian 0'Dowd}

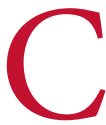

ross-regulatory work is underway to create an evidence base for defining what is serious enough for the health regulators to treat as a fitness to practise case and allow them to use their time more effectively, the $B D J$ can reveal.

Dental and nursing regulators the General Dental Council (GDC) and the Nursing and Midwifery Council (NMC) are putting out a piece of research to tender that will seek to understand better what they should be focusing on in fitness to practise (FtP) cases.

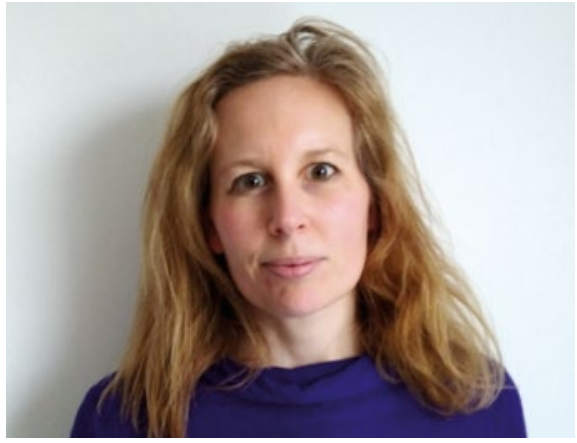

Rebecca Cooper, Head of Policy and Research Programme at the GDC
The research project entitled Developing the concept of seriousness in professional regulation will gather evidence to understand what it is that FtP should focus on and look across regulators to identify what affects public confidence and what regulators should do about that.

The GDC has been criticised in the past for not always focusing on matters that warrant FtP attention and spending time on cases that should have been dealt with elsewhere, such as in a dental practice or through the NHS.

Since publishing its Shifting the Balance agenda $^{1}$ in January 2017, the GDC has taken steps to improve the process of dental regulation and refocus FtP to be clear about the serious nature of 'impaired fitness to practise.'

In its subsequent Moving upstream report ${ }^{2}$ published in January 2019, the regulator first announced some details of various pieces of research it intended to carry out this year to boost this drive.

The new joint research, which will begin in the summer and report next year, will not produce a specific definition or list of what is 'seriousness' in FtP, but will lead to a

\section{Box: Research on informed consent}

The GDC is also working on research on ensuring health professionals get informed consent from their patients before treating them.

The GDC is working with the General Osteopathic Council (GOsC) and the Collaborating Centre for Values-Based Practice in Health \& Social Care for its Value-Based Practice in Dentistry project.

Rebecca Cooper said: 'The primary objective of this project is to develop a decision-making framework and series of tools that can be used by professionals and patients during a consultation to ensure informed consent is reached.

'The project is also seeking to provide a body of evidence and analysis that can be used to support professionals to develop and improve their skills.'

As part of ongoing dialogue about research with the other healthcare regulators, it had become clear that both the GDC and the GOsC had found evidence that informed consent was an issue of concern amongst respective patient groups, she added.

'Therefore, it made sense for us to collaborate on research to gain further insight to this important issue Following initial work with an advisory group of stakeholders, academics and patients, we are now in the process of developing the tools.

'Once they are ready, the plan is to have a period of piloting their use in academic and clinical settings, after which we will evaluate our findings in collaboration with GOsC and publish the results. We are at an early stage of this project, but the plan is for the initial publication in mid-2020.' 'framework' allowing the regulators to produce clearer policy and more helpful guidance to FtP panels as well as more evidence informed guidance to decision makers about what warrants the attention of FtP.

It will provide more information that goes beyond what is currently provided to decision makers as part of the FtP process and public information about the types of things that are a matter for the GDC and things that would be better dealt with elsewhere.

Rebecca Cooper, Head of Policy and Research Programme at the GDC, told the $B D J$ : 'There is a degree of subjectivity when you consider the concept of seriousness. The aim of the research is to reach a clear and shared understanding of what 'serious' means in the context of public safety and confidence, and to ensure we have a clear evidence base for this.

'We are undertaking this work to develop a greater understanding of the factors that should influence decision making throughout the fitness to practise process and to explore the perceived need for regulatory intervention in areas not directly connected to the professional's practice or public role, particularly in relation to how this behaviour impacts on public confidence.

'This is important not just for the regulation of dentistry but across all healthcare, and therefore we are working with the other healthcare regulators on this research.

The project involves a literature review to build a cross-regulatory picture of how misconduct and impairment are dealt with, and further research and engagement with patients and professionals to establish attitudes towards professional conduct and seriousness.

This type of collaborative working between the regulators is unusual, Ms Cooper admits, saying: 'Whilst we have had an ongoing dialogue with our fellow regulators for some time, devising and delivering research projects jointly is a more recent development.

'I think it's fair to say that these projects signal our intent to work much more closely with partners and this year we are undertaking work to develop our approach not just to working with the other regulators, but also with wider stakeholders and, indeed, the public, to achieve co-production in our research in a more robust way.

'In developing the outline for this research project, we approached all the UK 
4 healthcare regulators as the findings should have a clear application and relevance to regulation across all of healthcare. All the regulators have indicated their agreement to be involved in some form but the level of involvement that each body could make understandably varied dependant on capacity and existing commitments.'

Once the research is completed, it is anticipated that the resulting framework will help to inform various areas of the regulator's work, according to Ms Cooper.

This would include developing proportionate guidance for decision makers based on evidence on what affects public confidence in professions (particularly in dentistry) and establishing a clear link between FtP decisions at all stages of the process and the GDC's statutory objectives of protecting patients and maintaining public confidence.

In addition, it would allow the regulator to have the ability to better articulate to the profession why conduct and professionalism mattered and to feed this into its plans for learning based regulation.
There could also be a review of the standards for the dental team, examining the role they play in FtP proceedings and how they related to the concept of professional misconduct.

\section{References}

1. General Dental Council. Shifting the balance: a better fairer system of dental regulation. 2017). Available at https://www.gdc-uk.org/about/what-we-do/shifting-the-balance (accessed March 2019).

2. General Dental Council. Moving Upstream. 2019. Available at https://www.gdc-uk.org/about/whatwe-do/shifting-the-balance/moving-upstream (accessed March 2019).

\section{Editor Q\&A: Robert Wassell}

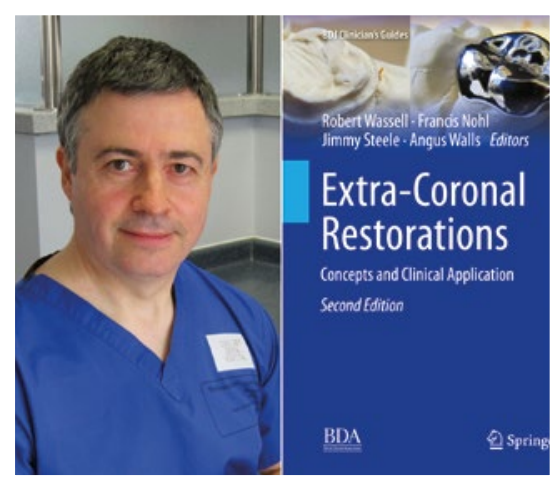

The BDJ, in association with the BDA, has published the second edition of ExtraCoronal Restorations, ${ }^{1}$ part of the series of books: the BDJ Clinician's Guides. This series builds on the trusted BDJ Clinical Guides, creating books that update and inform the busy clinician on key topics across all fields of dentistry. Each volume is authored by recognised experts, superbly illustrated and provides concise, highly practical guidance and solutions. For Extra-Coronal Restorations, we spoke to the lead editor Robert Wassell to find out more about it.

\section{Why should people read this book?}

In 2002 the BDJ published Crowns and Other Extra-Coronal Restorations, a landmark series and clinical guide for restoring individual teeth. This second edition of the book, simply entitled Extra-Coronal Restorations, is a very timely update. The book is completely restructured, has four new chapters, and comprehensively addresses key issues.

\section{Who is it aimed at?}

The emphasis of Extra-Coronal

Restorations is both on relevant science and practical dentistry. So, the aim is to appeal broadly from senior dental undergraduates and postgraduates through to practising dentists and academics.

\section{Did you enjoy writing it?}

Absolutely - just look at the list of contributing authors and editors! I am blessed to have such great colleagues. A few weeks before he died, Jimmy Steele asked if I was proud of the book, which was then in its final draft. Sadly, he did not see it published, but I am sure he too would have been delighted with what we achieved.

\section{What made you write it?}

Although popular, the first edition was getting outdated. So, it needed complete revision and restructuring. Jimmy helped devise the new structure and with that, we were into open water.

\section{What are the key issues in this area?}

Over the past two decades there have been important developments and changes, for example the significant shift to adhesive dentistry. So, to de-emphasise the wholesale use of crowns, the title has changed simply to Extra-Coronal Restorations. This new edition also reflects the major advances in materials, including developments in digital dentistry and in high strength ceramics. To ensure restorations are successful, we emphasise A Healthy Start and Managing Future Risk, subjects often covered superficially or not at all in other operative texts.

\section{Any advice for future authors of $B D J$ Clinician's Guides?}

Don't do it - unless you fully commit to the project! However, you don't have to be a J K Rowling and write a whole book. Some $B D J$
Guides, like Extra-Coronal Restorations, are edited works involving multiple authors who each write one or more chapters. This can be a worthwhile experience, particularly if you have or are developing expertise.

Before deciding to contribute to a new or revised Guide be sure the editors have a clear plan and there is a gap in the market. Keep your target readers in mind as you write. Decide which photographs and diagrams you want to use before writing. Be consistent with the style of diagrams and remember that Springer requires them to be in $800 \mathrm{dpi}$ if you commission an artist this information is critical and remember to agree costings for artwork up front. Everyone should use the same bibliography software, and finally, ensure you meet agreed deadlines!

\section{What do you do in your spare time?}

Family life takes precedence. My wife, Veronica, and I often travel to see our daughters in London and Paris which is wonderful, as is seeing friends. I am often out cycling, but I probably spend as much time maintaining bikes as riding them. A career spent restoring occlusions translates easily into bicycle mechanics.

\section{What other dentistry books would you highly recommend?}

If you want a concise book on occlusion why not try Applied Occlusion from Quintessence. It complements and enhances much of our advice in Extra-Coronal Restorations.

\section{References}

1. Wassell R, Nohl F, Steele J, Walls A. Extra-Coronal Restorations: Concepts and Clinical Application. Springer Nature: London, 2019. Available at https://shop.bda. org/extra-coronal-restorations (accessed March 2019). 